\title{
Salt crystallization in porous construction materials I Estimation of crystallization pressure
}

\author{
A. La Iglesia ${ }^{\mathrm{a}, *}$, V. González ${ }^{\mathrm{b}}$, V. López-Acevedo ${ }^{\mathrm{c}}$, C. Viedma ${ }^{\mathrm{c}}$ \\ a Instituto de Geología Económica del CSIC. Facultad de Ciencias Geológicas, UCM, E-28(1)4() Madrid. Spain \\ ${ }^{\mathrm{b}}$ Departamento de Química, ETSI, Agrónomos, UPM, E-28041) Madrid, Spain \\ 'Departamento de Cristalografia y. Mineralogía, Facultad de Ciencias Geológicas, UCM, E-28(1)4() Madrid. Spain
}

\begin{abstract}
The crystallization process of soluble salts inside the natural and artificial porous materials partially immersed in different saline solutions has been studied. This procedure is used to simulate the conditions of exposure to salt weathering in which foundations and lower walls of building structures are within the zone of capillary rise of saline ground water.

Crystallization pressures that can develop in the samples, which are a function of the pore size and salt-solution interfacial tension, have been calculated and are compared with experimental values of the materials tensile strength, since both these parameters allow the prediction of porous materials behaviour against salt weathering.
\end{abstract}

Keywords: Salt weathering; Porous media; Salt crystallization; Crystallization pressure

\section{Introduction}

The crystallization process of soluble salts in porous materials can generate pressures inside the pores sufficient to exceed the elastic limit of the material, causing its breakage. This phenomenon, since time immemorable, has been one of the major causes for the deterioration of rock materials in arid climates or in environments close to the sea [1-5].
The problem of crystallization pressure of salt was first studied by Correns [6], who presented a workable equation based on the Riecke principle from which the pressure generated $P$ versus salt supersaturation may be calculated:

$P=\mathrm{R} T / V_{\mathrm{s}} \ln \left(C / C_{\mathrm{s}}\right)$,

where $V_{\mathrm{s}}$ is the molar volume of solid salt, $C$ the concentration of salt solution and $C_{S}$ the solubility of salt at temperature $T$.

The variation of the molar volume of a salt on changing its state of hydration can generate elevated pressures in pores and fissures. Thus, for example, the molar volume of $\mathrm{Na}_{2} \mathrm{SO}_{4}$ may increase by 
240 times when it transforms into $\mathrm{Na}_{2} \mathrm{SO}_{4}$. $10 \mathrm{H}_{2} \mathrm{O}$, this effect being used in laboratory alteration studies on rocks [7]. The German Geomorphologist Mortensen [8] first recognized the importance of salt hydratation as a disintegrating factor in desert weathering and attempted the calculation of hydration pressures. This work was later continued by Winkler and Wilhelm [9].

It was recognized many years ago that the textural characteristics of porous system is an important factor in determining the crystallization pressure in rocks. Thus, Shaffer [10] indicates that salt damage is higher in materials of high microporosity compared to those of low one.

The theoric problem of the crystallization pressure of salt in porous media was resolved by Fitzner and Snethlage [11] following the thermodynamics of freezing mechanisms in porous materials developed by Everet [12]. According to these authors, salt crystals grow preferentially in the largest pores and the salt solution is withdrawn from the smaller pores. When a coarse pore is filled with crystals, crystallization continues in the smaller pores connected to it, but a crystallization pressure $P$ is then necessary which can be expressed according to Fitzner and Snethlage [11] as

$P=2 \sigma(1 / r-1 / R)$,

where $\sigma$ is the salt-solution interfacial tension, $r$ and $R$ are the radii of the small and coarse pores, respectively. Employing this equation RossiManaresi and Tucci [13] determined the crystallization pressure of gypsum in a porous material and La Iglesia et al. [14] amplified the method to include the crystallization of soluble salts.

According to Söhnel $[15,16]$, a reliable estimate of the electrolyte-crystal aqueous solution interfacial tension $\sigma$ for substances with solubility lower than approximately $1 \mathrm{~mol} / \mathrm{l}$ can be obtained from the equation:

$\sigma=k T \ln \left(C_{\mathrm{x}} / C_{\mathrm{s}}\right) / h a$,

where $k$ is the Boltzmann constant, $T$ the temperature $(\mathrm{K}), C_{\mathrm{x}}=\rho / \boldsymbol{M}$ the concentration in the crystal, $C_{\mathrm{s}}$ the solubility of salt at temperature $T, h$ the hydration number, $a=\left(M / v \rho N_{\mathrm{A}}\right)^{2 / 3}$ the surface area per ion, $M$ the molecular weight, $\rho$ the solid density, $v$ the number of ions in a formula unit, and $N_{\mathrm{A}}$ the number of Avogadro. For soluble salts, where $C_{\mathrm{s}}>1 \mathrm{~mol} / \mathrm{l}$, an estimate of $\sigma$ can be obtained on the basis of the expression suggested by Kahlweit [17]:

$\sigma=1.9 \times 10^{9} \Delta H_{\mathrm{C}} /\left(V_{\mathrm{S}} N_{\mathrm{A}}\right)^{1 / 3}$,

where $\Delta H_{C}$ is the heat of crystallization.

In engineering materials the tensile strength $\sigma_{\mathrm{t}}$ is the quantity which on a macroscopic level reflects the cohesive strength of the solid, governing the maximum load per surface area which can be supported without fracture. When the crystallization pressure surpasses the tensile strength $\sigma_{t}$ the material is damaged.

In this article the crystallization process of soluble salts in a number of different porous materials is studied, and the crystallization pressures calculated and compared to their experimentally measured tensile strengths.

\section{Experimental procedure}

Two types of building stones, both carbonatic rock, were selected and an artificial sample of calcium carbonate agglomerate was used as a reference material with a homogeneous texture. The building stones used were:

- Limestone of Colmenar (Madrid, Spain); this rock has been described by Dapena et al. [18] and was used extensively in sculptures and construction of monuments throughout the center of Spain (in Madrid Royal Palace, El Prado National Museum, Alcala Gate, National Librery,San Jeronimo the Royal Monastery, etc.).

- Dolostone of Cerro de la Rosa (Toledo, Spain); this material has been described by La Iglesia et al. [14], it was used in the construction of some well-known monuments in Toledo (Cathedral and the Monastery of San Juan de los Reyes).

In the initial tests $0.5 \mathrm{M} \mathrm{Na}_{2} \mathrm{SO}_{4}, \mathrm{~K}_{2} \mathrm{SO}_{4}$ and $\mathrm{MgSO}_{4}$ solutions were mixed in the adequate volumetric ratios to obtain the various solutions shown in Table 1. The ionic concentration of the solutions allows the crystallization of simple salts 
Table 1

Concentration $(\mathrm{mol} / \mathrm{l})$ of the salt solutions in the experiments

\begin{tabular}{llll}
\hline Solution & $\mathrm{Na}_{2} \mathrm{SO}_{4}$ & $\mathrm{~K}_{2} \mathrm{SO}_{4}$ & $\mathrm{MgSO}_{4}$ \\
\hline $\mathrm{Na}$ & 0.500 & 0 & 0 \\
$\mathrm{Na}: \mathrm{K}(3: 1)$ & 0.375 & 0.125 & 0 \\
$\mathrm{Na}: \mathrm{K}(3: 2)$ & 0.300 & 0.200 & 0 \\
$\mathrm{Na}: \mathrm{K}(1: 1)$ & 0.250 & 0.250 & 0 \\
$\mathrm{Na}: \mathrm{K}(2: 3)$ & 0.200 & 0.300 & 0 \\
$\mathrm{Na}: \mathrm{K}(1: 3)$ & 0.125 & 0.375 & 0 \\
$\mathrm{~K}$ & 0 & 0.500 & 0 \\
$\mathrm{Mg}$ & 0 & 0 & 0.500 \\
$\mathrm{Mg}: \mathrm{K}(3: 1)$ & 0 & 0.125 & 0.375 \\
$\mathrm{Mg}: \mathrm{K}(3: 2)$ & 0 & 0.200 & 0.300 \\
$\mathrm{Mg}: \mathrm{K}(1: 1)$ & 0 & 0.250 & 0.250 \\
$\mathrm{Mg}: \mathrm{K}(2: 3)$ & 0 & 0.300 & 0.200 \\
$\mathrm{Mg}: \mathrm{K}(1: 3)$ & 0 & 0.375 & 0.125 \\
\hline
\end{tabular}

such as: $\mathrm{K}_{2} \mathrm{SO}_{4}, \quad \mathrm{Na}_{2} \mathrm{SO}_{4}, \quad \mathrm{Na}_{2} \mathrm{SO}_{4} \cdot 1 \mathrm{OH}_{2} \mathrm{O}$, $\mathrm{MgSO}_{4} \cdot 7 \mathrm{H}_{2} \mathrm{O}$ and mixed salts such as: $\mathrm{K}_{2} \mathrm{Mg}\left(\mathrm{SO}_{4}\right)_{2} \cdot 6 \mathrm{H}_{2} \mathrm{O}, \quad \mathrm{K}_{2} \mathrm{Mg}\left(\mathrm{SO}_{4}\right)_{2} \quad$ and $\mathrm{K}_{3} \mathrm{Na}\left(\mathrm{SO}_{4}\right)_{2}$.

A method of controlling the supply of salt to the specimen rock material, similar to that described by Sperling and Cooke [19] was used; samples were continuously and partially immersed in a constant volume of ionic solution, allowing capillary rise, concentration by evaporation and crystallization of the salt in a narrow zone of the sample. This procedure simulates the situation in which foundations and lower walls of the buildings are within the zone of capillary rise of saline ground water and consequently exposed to salt weathering. Instead of $30 \mathrm{~mm}$ edge cubic samples used by Sperling and Cooke [19], $120 \times 15 \times 15 \mathrm{~mm}$ prisms in natural samples and $10 \mathrm{~mm}$ diameter by $80 \mathrm{~mm}$ high cylinders of calcium carbonate agglomerate samples were employed for this study. In all the cases, the immersion in salt solutions was of a constant depth of $10 \mathrm{~mm}$.

The experiments were carried out in ambient conditions without control of temperature and relative humidity (variation interval of both parameters, $16-28^{\circ} \mathrm{C}$ and $30-60 \%$ ). The calcium carbonate agglomerate samples were treated for $15 \mathrm{~d}$ and the building stone samples were exposed to saline solution for three months. At the end of this period, they were imbedded in an epoxy resin and cut parallel to their longest axis, so that any changes could be observed.

The porosity data were obtained by means of a Micromeritic 9310 mercury porosimeter. The tensile strength of the samples was determined indirectly by the Brazil test, using the procedure described by Brown [20]. This test is an alternative to the classical uni-axial tensile method, which is difficult to perfom to acceptable standards for brittle materials. The justification for the Brazil test is based on the experimental fact that the stress field which induces tensile failure, when a disc is compressed diametrally, can be fully determined. This test has received considerable attention in the fields of concrete testing. rock mechanics and ceramics technology. Data were collected from five specimens of each sample tested, and the tensile strength, $\sigma_{1}$ was calculated using the equation: $\sigma_{t}=2 F / \pi D t$, where $F$ is the load at failure and $D$ and $t$ are the diameter and the thickness of the test specimen, respectively.

\section{Results}

Several stages can be distinguished in the weathering of these materials, rise of saline solutions through the porous material, ion-enrichment in the solution due to evaporation and consequently, salt crystallization. The latter phenomenon is produced after $24 \mathrm{~h}$ of the immersion of agglomerate samples and after about a week in the rock samples. By X-ray diffraction the following phases were identified: $\mathrm{Na}_{2} \mathrm{SO}_{4} \cdot 10 \mathrm{H}_{2} \mathrm{O}$ (mirabilite), $\mathrm{Na}_{2} \mathrm{SO}_{4}$ (thenardite), $\mathrm{MgSO}_{4} \cdot 7 \mathrm{H}_{2} \mathrm{O}$ (epsomite), $\mathrm{K}_{2} \mathrm{SO}_{4} \quad$ (arkanite), $\mathrm{K}_{2} \mathrm{Mg}\left(\mathrm{SO}_{4}\right)_{2} \cdot 6 \mathrm{H}_{2} \mathrm{O}$ (picromerite) and $\mathrm{K}_{3} \mathrm{Na}\left(\mathrm{SO}_{4}\right)_{2}$ (aphthitalite). The crystals of aphthitalite and arkanite appear as subefflorescences which have grown in parallel bands within the porous material and are the major causes for failure. In another paper [21] we describe in more detail, the crystallization processes which occur in various materials studied.

Fig. 1 shows the pore volume distribution versus pore size of the studied materials. The natural samples had lower porosity than the calcium carbonate agglomerate, although with a higher proportion of 


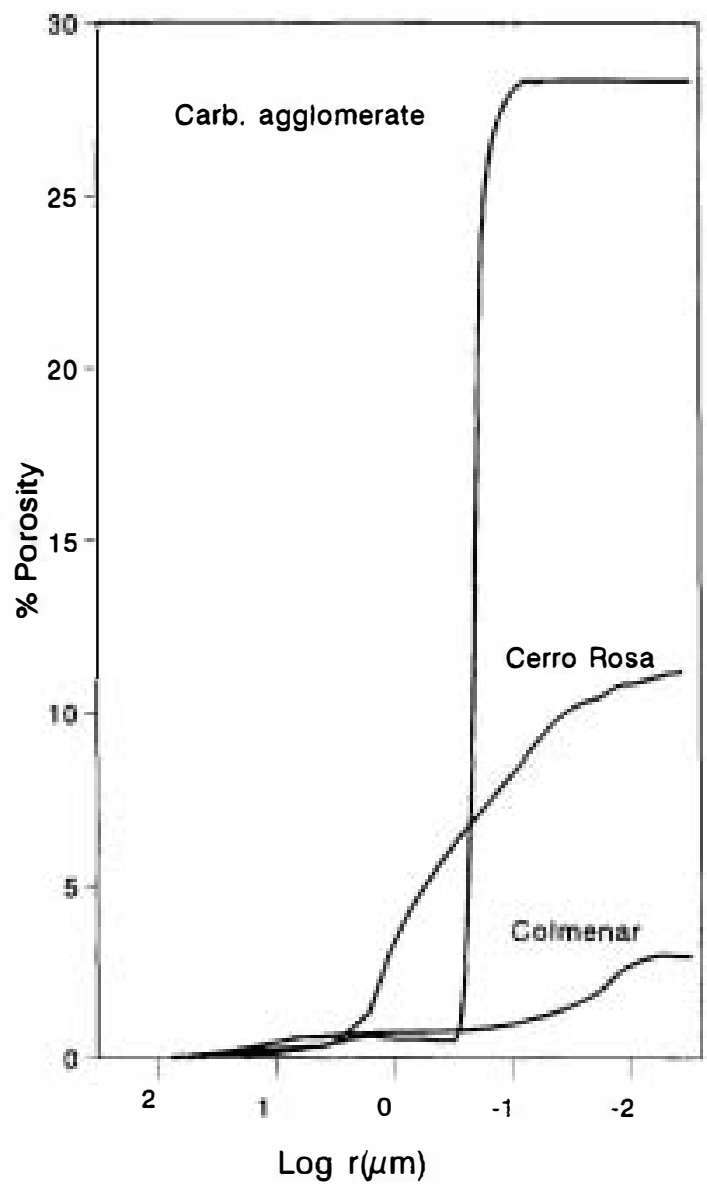

Fig. 1. Pore-volume distribution versus pore diameter of the studied samples.

pores with diameters less than $0.1 \mu \mathrm{m}$. The calcium carbonate agglomerate has a uniform pore-size distribution, mainly between 1 and $0.1 \mu \mathrm{m}$.
Following the method employed by RossiManaresi and Tucci [13], we have estimated the crystallization pressures that can develop in the materials under study. For this, we considered five classes of pores as a function of their radius (expressed in $\mu \mathrm{m}$ ): class I, $r<0.01$; class II, $0.01<r<0.1$; class III, $0.1<r<1$; class IV, $1<r<10$; class $\mathrm{V}, 10<r<100$. The following values of average radii for each class were taken: $0.0045,0.045,0.45,4.5$ and $45 \mu \mathrm{m}$, respectively. Using the data of the pore volume distribution versus pore diameter from Fig. 1, an estimate of the percentage pore volume of each pore class was made, the results of which are shown in Table 2.

To calculate the crystallization pressures in different classes we have taken $45 \mu \mathrm{m}$ as the constant value for R in Eq. (2), the values $r$ of the other classes and $0.064 \mathrm{~N} \mathrm{~m}^{-1}$ for $\sigma \mathrm{K}_{3} \mathrm{Na}\left(\mathrm{SO}_{4}\right)_{2}$ (Table 3) obtaining values of 28.44, 2.84, 0.28 and $0.03 \mathrm{M} \mathrm{Pa}$ for the theorical pressures which can build up when a coarse pore of class $\mathrm{V}$ is connected to smaller pores of classes I-IV.

The values of salt-solution interfacial tension, $\sigma$, of different salts were calculated employing Eq. (3) and the solubility data of Risacher and Fritz [22], the results are presented in Table 3.

To calculate the effective pressure which can arise in the material, it is necessary to take into account the volume percent of the pores of each class, $V_{r}$, which should be related to the volume percent of large pores $V_{R}$. The product of the factor $V_{r} / V_{R}$ for the theoretical pressure of each class permits calculation of the effective pressure value,

Table 2

Pore volume \% (A) and porosity \% (B) distribution in the samples

\begin{tabular}{|c|c|c|c|c|c|c|c|c|c|c|c|}
\hline \multirow[t]{3}{*}{ Sample } & \multirow[t]{3}{*}{ Total porosity $\%$} & \multicolumn{10}{|c|}{ Class of pore size } \\
\hline & & \multicolumn{2}{|c|}{$\begin{array}{l}\mathrm{I} \\
r<0.01\end{array}$} & \multicolumn{2}{|c|}{$\begin{array}{l}\text { II } \\
0.01<r<0.1\end{array}$} & \multicolumn{2}{|c|}{$\begin{array}{l}\text { III } \\
0.1<r<1\end{array}$} & \multicolumn{2}{|c|}{$\begin{array}{l}\text { IV } \\
1<r<10\end{array}$} & \multicolumn{2}{|c|}{$\begin{array}{l}\mathrm{V} \\
10<r<100\end{array}$} \\
\hline & & A & B & A & B & A & B & A & B & A & B \\
\hline Colmenar & 2.952 & 8.70 & 0.26 & 58.26 & 1.72 & 6.6 & 0.21 & 10.43 & 0.31 & 15.65 & 0.46 \\
\hline C. Rosa & 11.104 & 3.59 & 0.40 & 12.68 & 1.41 & 66.1 & 7.42 & 16.49 & 1.83 & 0.42 & 0.05 \\
\hline C. Agglomerate & 28.340 & 0 & 0 & 2.52 & 0.71 & 95.4 & 27.08 & 1.09 & 0.31 & 0.86 & 0.24 \\
\hline
\end{tabular}




\begin{tabular}{lccc}
\hline Compound & $\log K_{\mathrm{s}}$ & $\log C_{\mathrm{eq}}$ & $\sigma\left(\mathrm{N} \mathrm{m}^{-1}\right)$ \\
\hline $\mathrm{Na}_{2} \mathrm{SO}_{4}$ (thenardite) & -0.29 & -0.29 & 0.040 \\
$\mathrm{Na}_{2} \mathrm{SO}_{4} \cdot 10 \mathrm{H}_{2} \mathrm{O}$ (mirabilite) & -1.23 & -0.61 & 0.046 \\
$\mathrm{~K}_{2} \mathrm{SO}_{4}$ (arcanite) & -1.78 & -0.79 & 0.049 \\
$\mathrm{~K}_{3} \mathrm{Na}_{\left(\mathrm{SO}_{4}\right)_{2} \text { (aphthitalite) }}$ & -7.61 & -1.61 & 0.064 \\
$\mathrm{~K}_{2} \mathrm{Mg}_{\left(\mathrm{SO}_{4}\right)_{2} \cdot 6 \mathrm{H}_{2} \mathrm{O} \text { (picromerite) }}$ & -4.33 & -1.11 & 0.055 \\
$\mathrm{MgSO}_{4} \cdot 6 \mathrm{H}_{2} \mathrm{O}$ (hexahidrite) & -1.64 & -0.82 & 0.050 \\
$\mathrm{MgSO}_{4} \cdot 7 \mathrm{H}_{2} \mathrm{O}$ (epsomite) & -1.88 & -0.94 & 0.052 \\
\hline
\end{tabular}

Table 4

Pore-volume relation and calculated pressures of epsomite, aphthitalite or thenardite

\begin{tabular}{|c|c|c|c|c|c|c|c|c|c|c|}
\hline \multirow{2}{*}{$\begin{array}{l}\text { Salt } \\
\mathrm{Na}_{2} \mathrm{SO}_{4}\end{array}$} & \multirow{2}{*}{$\begin{array}{l}\text { Sample } \\
\text { Colmenar }\end{array}$} & \multicolumn{2}{|c|}{$\begin{array}{l}\text { Class I } \\
r=0.0045 \mu \mathrm{m}\end{array}$} & \multicolumn{2}{|c|}{$\begin{array}{l}\text { Class II } \\
r=0.045 \mu \mathrm{m}\end{array}$} & \multicolumn{2}{|c|}{$\begin{array}{l}\text { Class III } \\
r=0.45 \mu \mathrm{m}\end{array}$} & \multicolumn{2}{|c|}{$\begin{array}{l}\text { Class IV } \\
r=4.5 \mu \mathrm{m}\end{array}$} & \multirow{2}{*}{$\begin{array}{c}P \text { total }(\mathrm{MPa}) \\
16.65\end{array}$} \\
\hline & & 0.56 & 9.96 & 3.72 & 6.60 & 0.44 & 0.08 & 0.67 & 0.01 & \\
\hline & C. Rosa & 8.49 & 150.90 & 29.96 & 53.14 & 157.85 & 27.45 & 39.96 & 0.68 & 232.17 \\
\hline \multirow[t]{3}{*}{$\mathrm{K}_{3} \mathrm{Na}\left(\mathrm{SO}_{4}\right)_{2}$} & Colmenar & 0.56 & 15.93 & 3.72 & 10.56 & 0.44 & 0.13 & 0.67 & 0.01 & 26.63 \\
\hline & C. Rosa & 8.49 & 241.45 & 29.96 & 85.02 & 157.85 & 43.93 & 39.96 & 1.09 & 371.48 \\
\hline & C. Agglomerate & 0 & 0 & 2.93 & 8.32 & 110.97 & 30.87 & 1.27 & 0.04 & 39.23 \\
\hline $\mathrm{MgSO}_{4} \cdot 7 \mathrm{H}_{2} \mathrm{O}$ & Colmenar & 0.56 & 12.45 & 3.72 & 8.25 & 0.44 & 0.10 & 0.67 & 0.01 & 20.81 \\
\hline
\end{tabular}

$V_{r}=$ volume percent of the pores of each class; $V_{R}=$ volume percent of large pores; $P_{\mathrm{e}}=$ effective pressure.

$P_{\mathrm{e}}$. The sum of the effective pressure of each class will give the total pressure (tension) that the material will support when aphthitalite crystallizes. The values of the effective pressure calculated for the crystallization of aphthitalite, thenardite and epsomite in the artificial and natural samples are presented in Table 4.

The average values and standard deviations obtained from the determination of the tensile strength of the samples, expressed in MPa were as follows: Colmenar 8.333 (0.756), Cerro de la Rosa $5.845(0.542)$ and calcium carbonate agglomerate $0.834(0.018)$.

\section{Discussion}

The crystallization technique used in this study, based on the capillary rise, concentration by evaporation of the solution as it migrates through the porous structure, leads to the nucleation and crystal growth in a narrow zone of the materials, Fig. 2. Due to the continual contribution of saline solution an elevated ionic concentration is maintained in this zone, which permits crystallization in the small pores and the generation of pressures sufficient to produce cracking or even the disintegration of the aterial, Fig. 3. 


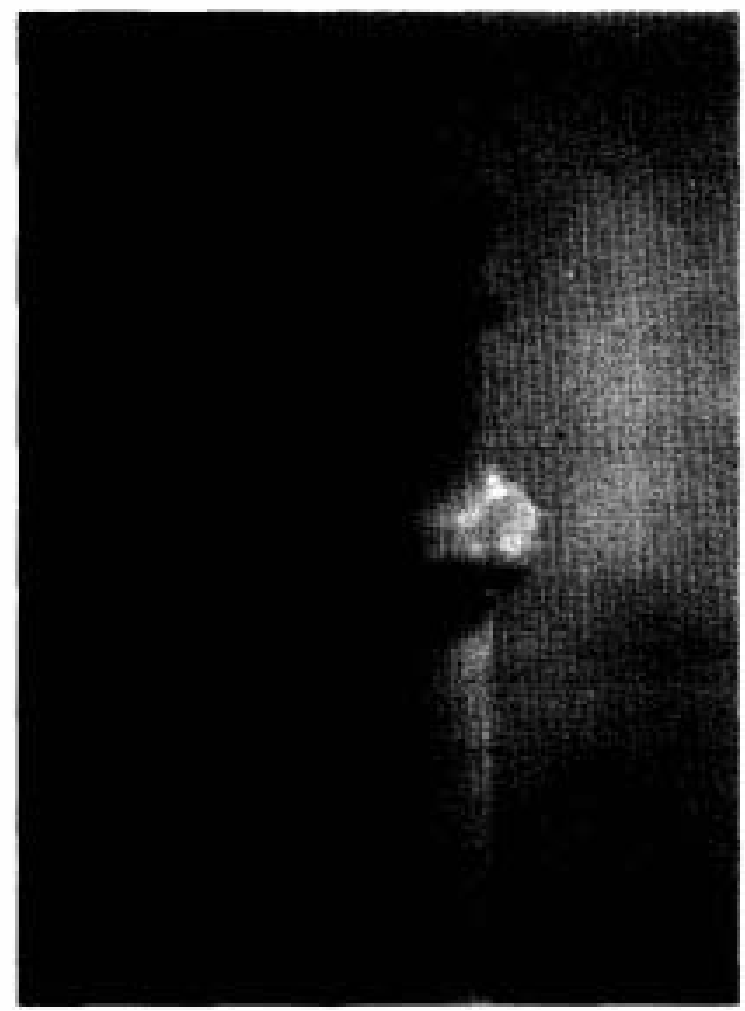

Fig. 2. Ring of salt crystallization in calciun carbonate agglomerate samples partially inmersed in $\mathrm{Na}: \mathrm{K}(3: 2)$ solution for $2 \mathrm{~d}$ in ambient conditions.

As indicated by Eq. (2), the pressure generated during crystallization depends upon the pore size and the salt-solution interfacial tension. Thus, these two factors will determine the stability of the material. With respect to the interfacial tension the order of the disruptive effect of the salts considered in this study (Table 3) was as follows: $\mathrm{K}_{3} \mathrm{Na}\left(\mathrm{SO}_{4}\right)_{2}>$ $\mathrm{K}_{2} \mathrm{Mg}\left(\mathrm{SO}_{4}\right)_{2} \cdot 6 \mathrm{H}_{2} \mathrm{O}>\mathrm{MgSO}_{4} \cdot 7 \mathrm{H}_{2} \mathrm{O}>\mathrm{MgSO}_{4}$ $6 \mathrm{H}_{2} \mathrm{O}>\mathrm{K}_{2} \mathrm{SO}_{4}>\mathrm{Na}_{2} \mathrm{SO}_{4} \cdot 10 \mathrm{H}_{2} \mathrm{O}>\mathrm{Na}_{2} \mathrm{SO}_{4}$.

According to Fitzner and Snethlage [11], salt crystallization in porous media takes place in the first moment in the largest pores and continues in the smaller pores. Thus, the filling of each class of pore in Table 2 may be related with the pressures calculated for the same class presented in Table 4. The variation of pressure against the percentage of pores filled in the three studied materials for the crystallization of $\mathrm{K}_{3} \mathrm{Na}\left(\mathrm{SO}_{4}\right)_{2}, \mathrm{NaSO}_{4}$ and

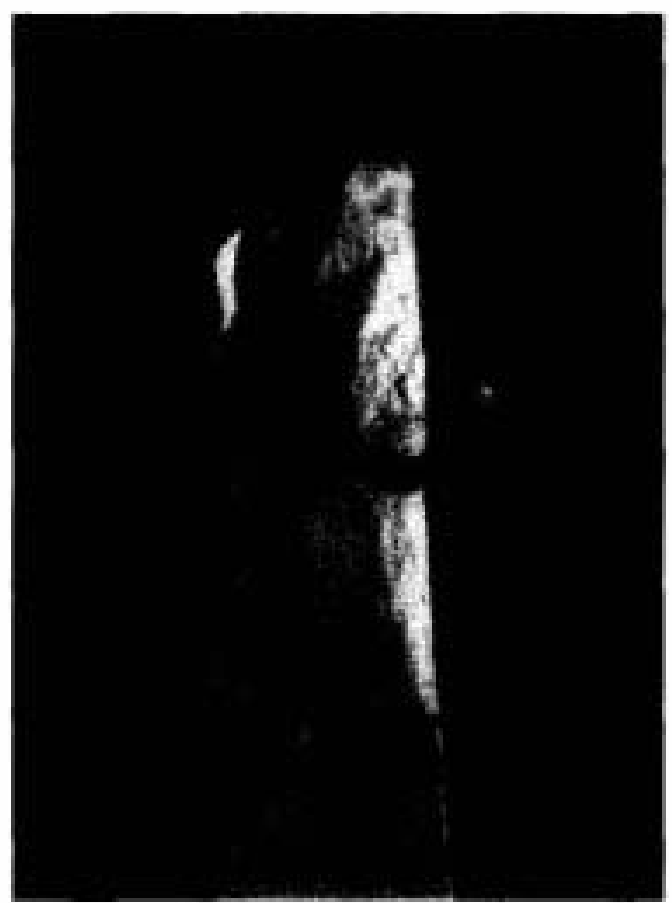

Fig. 3. Cracking of Cerro de la Rosa sample partially immersed in $\mathrm{Na}: \mathrm{K}(3: 1)$ solution for $12 \mathrm{~d}$ in ambient conditions.

$\mathrm{MgSO}_{4} \cdot 7 \mathrm{H}_{2} \mathrm{O}$ is shown in Fig. 4. As indicated in the figure, the behaviour of the materials is different. In the samples of calcium carbonate agglomerate and Cerro de la Rosa elevated crystallization pressures are reached (greater than $5 \mathrm{MPa}$ ) when approximately $30 \%$ of the pores are filled, whilst in the Colmenar sample these pressures are reached only when about $80 \%$ of the pores are filled. The behaviour of the various salts are also different. Those with high values of $\sigma$ produce greater pressures, an effect which rises on increasing the $\%$ of pores filled.

The disruptive effect of salt crystallization in porous media is due to the generation of crystallization pressures which are greater than the cohesive forces of the material. The uniaxial tensile strength, $\sigma_{t}$, reflects at a macroscopic scale these cohesive forces and represents the tensile load per surface unit which leads to the failure of the material. When the crystallization pressure, $P$, exceeds the tensile strength, $\sigma_{t}$, the material cracks. With this in mind the tensile strengths of the studied 

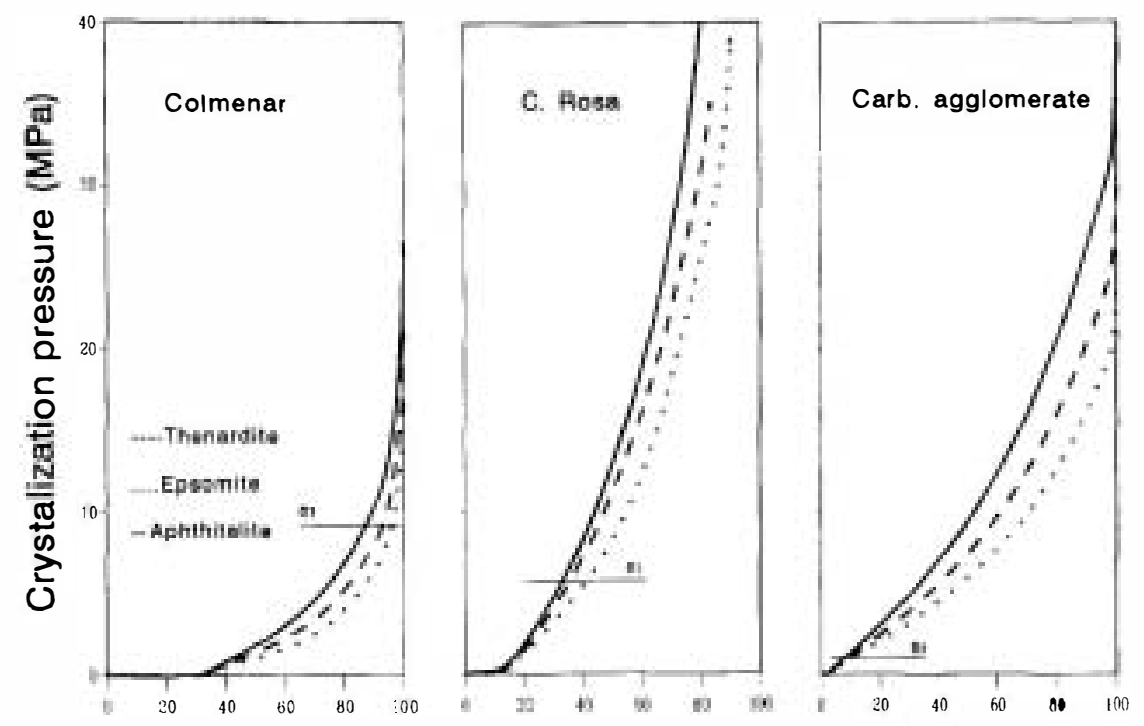

Filled pore volume (\%)

Fig. 4. Estimation of crystallization pressures for the various samples and salts. Values of tensile strength for all samples are shown.

samples were determined, these values are shown in Fig. 4 as continual horizontal lines. In the case of the Cerro de la Rosa and calcium carbonate agglomerate samples, the tensile strength limits were reached with low contents of any salt (30-40\% and $5-7 \%$, respectively). This confirms the breakage of these materials just after a few days in contact with the saline solutions. However, in the case of the Colmenar sample only after approximately $85 \%$ filling of the pores with $\mathrm{K}_{3} \mathrm{Na}\left(\mathrm{SO}_{4}\right)_{2}$ or $95 \%$ with $\mathrm{Na}_{2} \mathrm{SO}_{4}$, the crystallization pressure approaches the tensile strength limit, justifying the stability of this material, even after being in contact with the saline solutions for 3 months.

\section{Conclusions}

From the results obtained the following conclusions may be drawn:

- The proposed salt crystallization method in porous media. based on capillary rise and concentration by evaporation and consequent crystallization allows the simulation, in a short- time period, of salt weathering processes on building stone materials.

- With the knowledge of the pore volume, poresize distribution and the tensile strength, the behaviour of the material due to salts may be predicted.

- The crystallization pressure produced in a porous media is proportional to the salt-solution interfacial tension and the last magnitude is related the solubility of the salt by Eq. (3). The results obtained in this study allow the classification of the disruptive effect of the studied salts as follows: aphthitalite $>$ picromerite $>$ epsomite $>$ arcanite $>$ mirabilite $>$ thenardite.

- The calculated values of the crystallization pressures in the studied samples were greater than the tensile strengths measured, even in materials with low percentages of small pores. A continuous supply of saline solution in an environment which permits their saturation would cause, with time, the breakage of these materials. Thus, this study highlights the risk of salt weathering to building stone materials in arid climates or in those with proximity to the sea which can suffer attack from salt mist. 


\section{Acknowledgements}

The authors wish to thank the Comunidad Autonoma of Madrid for the financial support of the projects 0061/94 and 0126/94.

\section{References}

[1] R.U. Cooke and I.J. Smalley, Nature 220 (1968) 1226.

[2] I.S. Evans, Revue de Geomorphologie Dynamique 19 (1970) 155.

[3] E.M. Vinkler, Stone: Properties, Durability in Man's Evironment, (Springer, New York, 1975) p. 229.

[4] K. Zhender and A. Arnold, GP News Lett. 4 (1983) 2.

[5] K. Zhender and A. Arnold, Stud. Conserv. 29 (1984) 32.

[6] C.W. Correns, Disc. Faraday Soc. 5 (1949) 267.

[7] American Society for Testing Materials, ASTM C 88, Standard Test Method for Soundness of Aggregates by use of sodium sulfate and magnesium sulfate, Annual Book of ASTM Standard (1990).

[8] H. Mortensen, P. Geog. Mitt. (1933) 130.

[9] E.M. Winkler and E.J. Wilhelm, Geol. Soc. Ameri. Bull. 81 (1970) 567.
[10] R.J. Shaffer, The Weathering of Natural Building Stones. DSIR, Build. Res. Special Report No. 18 Stationary Office, London (1932) p. 34.

[11] B. Fitzner and R. Snethlage, GP News Lett. 3 (1982) 13.

[12] D.H. Everet, Trans. Faraday Soc. 57 (1961) 1541.

[13] R. Rossi-Manaresi and A. Tucci, in: Proc 1st Symp. Bari The Conservation of Monuments in the Mediterranean Basin. (1989) p. 97.

[14] A. La Iglesia, M.A. Garcia del Cura and S. Ordóñez, Sci. Total Environ. 152 (1994) 179.

[15] O. Söhnell, J. Crystal Growth 57 (1982) 101.

[16] O. Söhnel, J. Crystal Growth 63 (1983) 174.

[17] M. Kahlweit, Z. Phys. Chem. 28 (1961) 245.

[18] E. Dapena, M.A. Garcia del Cura and S. Ordoñez, in: Engineering Geology of Ancient Works, Monuments and Historical Sites, Eds. Marinos and Koukis (Balkema, Rotterdam, 1988) p. 683.

[19] C.H.B. Sperling and R.U. Cooke, Earth Surface Process and Landforms 10 (1985) 541.

[20] E.T. Brown, Rock Characterization Testing and Monitoring ISRM Suggested Methods, (Pergamon, New york, 1981) p. 242.

[21] V. López-Acevedo, C. Viedma, V. González and A. La Iglesia, J. Crystal Growth, submitted.

[22] F. Risacher and B. Fritz, Sci. Geol. Bull. 37 (1984) 329. 